\title{
PENERAPAN METODE TAGUCHI UNTUK ANALISIS KEKUATAN TEKAN BATAKO
}

\author{
SHINTA YULIANA, YUDIANTRI ASDI, FERRA YANUAR \\ Program Studi Matematika, \\ Fakultas Matematika dan Ilmu Pengetahuan Alam, Universitas Andalas, \\ Kampus UNAND Limau Manis Padang, Indonesia, \\ email : sshintayyuliana@gmail.com
}

\begin{abstract}
Pada zaman modern ini, pembangunan konstruksi gedung dan perumahan di kota-kota besar berkembang sangat pesat. Hal ini mengakibatkan kebutuhan akan bahan bangunan akan meningkat pula. Salah satu bahan bangunan yang sering digunakan dalam konstruksi gedung dan perumahan adalah batako. Batako merupakan bahan bangunan yang berupa bata cetak alternatif pengganti batu bata yang tersusun dari komposisi antara semen, agregat (pasir dan kerikil) dan air. Dalam penelitian ini digunakan desain eksperimen metode Taguchi dengan rancangan fractional factorial $3^{4}$ yaitu menggunakan empat faktor (agregat, semen, air dan lama pengeringan) dan tiga level (agregat : 10, 12, $14 \mathrm{Kg}$; semen : 0.4, 0.6, $0.8 \mathrm{Kg}$; air : 0.6, 0.8, $1 \mathrm{~L}$ dan lama pengeringan : $3,5,7$ hari) dengan jenis karakteristik kualitas larger is better untuk mendapatkan komposisi bahan batako yang lebih kokoh (robust). Hasil penelitian menunjukkan bahwa faktor-faktor yang mempengaruhi karakteristik kualitas kuat tekan pada batako yaitu semen dan agregat. Sedangkan komposisi bahan optimal yang diusulkan berdasarkan hasil penelitian untuk satu buah batako adalah dengan level faktor yang terpilih agregat $=10 \mathrm{Kg}$, semen $=0.8 \mathrm{Kg}$, air $=1 \mathrm{~L}$ dan lama pengeringan $=3$ hari. Untuk kuat tekan batako optimal yang didapatkan dari penelitian ini yaitu sebesar 0.7259 $\mathrm{MPa}$.
\end{abstract}

Kata Kunci: Batako, fractional factorial, kuat tekan, metode Taguchi, orthogonal array

\section{PENDAHULUAN}

Pada zaman modern ini, pembangunan konstruksi gedung dan perumahan di kotakota besar berkembang sangat pesat. Hal ini mengakibatkan kebutuhan akan bahan bangunan akan meningkat pula. Peningkatan akan kebutuhan bahan bangunan juga diiringi dengan meningkatnya kualitas dari bahan bangunan tersebut. Salah satu bahan bangunan yang sering digunakan dalam konstruksi gedung dan perumahan adalah batako.

Batako merupakan bahan bangunan yang berupa bata cetak alternatif pengganti batu bata yang tersusun dari komposisi antara semen, agregat (pasir dan kerikil) dan air. Batako digunakan untuk dinding bangunan nonstruktural, yaitu sebagai dinding pengisi yang harus diperkuat oleh rangka. Apabila dinding tidak mampu menahan gaya, maka akan terjadi pergeseran yang akan mengakibatkan gangguan pada batako. Supaya tidak terjadi gangguan pada batako maka batako harus memiliki kuat tekan maksimum.

Pada umumnya, banyak masyarakat menggunakan batako sebagai bahan bangunan. Hal ini dapat menciptakan persaingan untuk mempertahankan kualitas 
batako demi kepuasan konsumen. Untuk mempertahankan dan memperbaiki kualitas batako dapat dicapai dengan pengendalian kualitas yang tepat. Dalam penelitian ini digunakan pengendalian kualitas secara Off-line Quality Control yang dilakukan pada tahap awal dan bersifat preventif. Salah satu metode pengendalian kualitas secara Off-line Quality Control adalah metode yang diusulkan oleh Dr. Genichi Taguchi, yang dikenal sebagai metode Taguchi. Metode Taguchi digunakan untuk memperbaiki kualitas produk dan proses, mengoptimalkan rancangan produk dan proses, serta dapat menekan biaya dan resources seminimal mungkin [1].

Dalam acuan ini, untuk menghasilkan batako yang memiliki kuat tekan maksimum perlu diketahui faktor-faktor yang berpengaruh besar pada batako. Untuk itu digunakan metode Taguchi dengan rancangan fractional factorial $3^{4}$ yaitu menggunakan 4 faktor dan 3 level dengan jenis karakteristik kualitas larger is better.

Tujuan dalam acuan ini adalah :

(1) Untuk mengetahui faktor-faktor yang berpengaruh secara signifikan terhadap nilai kuat tekan batako.

(2) Untuk mengetahui kombinasi level untuk masing-masing faktor sehingga menghasilkan batako yang memiliki kuat tekan maksimum.

\section{LANDASAN TEORI}

\subsection{Metode Taguchi}

Metode Taguchi pertama kali dicetuskan oleh Dr. Genichi Taguchi pada tahun 1949 saat mendapat tugas untuk memperbaiki sistem komunikasi di Jepang. Metode Taguchi merupakan suatu metode pengendalian kualitas sebelum proses berlangsung atau sering disebut off-line quality control yang sangat efektif dalam peningkatan kualitas dan juga mengurangi biaya. Rekayasa kualitas yang diusulkan Taguchi bertujuan untuk performasi produk sehingga tidak sensitif terhadap faktor yang tidak dapat dikendalikan [2].

\subsubsection{Orthogonal Array}

Orthogonal array (OA) merupakan salah satu bagian fractional factorial experiment (FFE). FFE merupakan percobaan yang menggunakan rancangan faktorial sebagian (tidak lengkap). Bagian ini mungkin hanya sepertiga, sepersembilan, atau seperdua puluh tujuh dan seterusnya disesuaikan dengan jumlah faktor dan jumlah level yang digunakan [1]. Orthogonal array dinotasikan dengan

$$
L_{n}\left(l^{f}\right)
$$

dimana $L$ : simbol orthogonal array, $n:$ jumlah baris, $l:$ jumlah level, dan $f:$ jumlah faktor.

\subsubsection{Penggunaan Signal To Noise Ratio}

Signal To Noise Ratio (SNR) merupakan logaritma dari suatu fungsi kerugian kuadratik dan digunakan untuk mengevaluasi kualitas suatu produk [1]. SNR juga 
digunakan untuk megidentifikasi faktor-faktor yang mempengaruhi suatu produk. Perhitungan SNR yang dilakukan tergantung dari karakteristik kualitas yang dituju. Secara umum, SNR diperoleh dari persamaan berikut [2]:

$$
S N R=-10 \log _{10}(M S D),
$$

dengan MSD (Mean Squared Deviation) yang berbeda pada masing-masing karakteristik $S N R$.

Menurut Taguchi ada tiga jenis karekteristik $S N R$ [2], yaitu:

(1) Nominal is the best, merupakan karakteristik kualitas yang menuju suatu nilai tertentu. Nilai $S N R$ adalah:

$$
S N R=-10 \log _{10}\left(\frac{1}{r} \sum_{i=1}^{r}\left(y_{i}-y_{0}\right)^{2}\right)
$$

dimana r: banyak ulangan, $y_{0}$ : nilai respon dan $y_{i}$ : jumlah semua hasil percobaan pada run ke- $i$.

(2) Smaller is better, merupakan karakteristik kualitas yang nilainya apabila semakin kecil (nol adalah nilai idealnya) semakin baik. Nilai SNR adalah:

$$
S N R=-10 \log _{10}\left(\frac{1}{r} \sum_{i=1}^{r}\left(y_{i}\right)^{2}\right)
$$

(3) Larger is better, merupakan karakteristik kualitas yang nilainya apabila semakin besar semakin baik (tak terhingga sebagai nilai idealnya). Nilai $S N R$ adalah:

$$
S N R=-10 \log _{10}\left(\frac{1}{r} \sum_{i=1}^{r} \frac{1}{\left(y_{i}\right)^{2}}\right)
$$

\section{DATA DAN METODE PENELITIAN}

\subsection{Sumber Data}

Data yang digunakan dalam penelitian ini merupakan data primer yang diperoleh secara langsung dengan melakukan percobaan. Percobaan dilakukan di tempat pembuatan batako yang bertempat di Kapalo Koto, Limau Manis, Padang, Sumatera Barat.

\subsection{Identifikasi Variabel}

Variabel yang akan digunakan dalam penelitian ini yaitu terdiri dari variabel tak bebas (kuat tekan batako) dan variabel bebas terdiri dari empat faktor yaitu semen, agregat, air dan lama pengeringan yang disimbolkan dengan A, B, C, dan D dengan masing-masing tiga level seperti pada Tabel 1.

\section{HASIL DAN PEMBAHASAN}

Pada penelitian ini, digunakan batako berbentuk kubus yang memiliki sisi $15 \mathrm{~cm}$. Satuan dari nilai kuat tekan batako adalah Mega Pascal (MPa). Ada faktor noise dalam proses pembuatan batako yaitu cuaca (kelembaban dan suhu), perbandingan antara pasir dan kerikil pada agregat. 
Tabel 1. Kode Level Nilai Variabel

\begin{tabular}{|c|c|c|c|c|}
\hline \multirow{2}{*}{ Faktor } & \multirow{2}{*}{ Kode Level } & \multicolumn{3}{|c|}{ Level } \\
\cline { 3 - 5 } & & 1 & 2 & 3 \\
\hline Agregat $(\mathrm{Kg})$ & $\mathrm{A}$ & 10 & 12 & 14 \\
\hline Semen (Kg) & $\mathrm{B}$ & 0.4 & 0.6 & 0.8 \\
\hline Air (L) & $\mathrm{C}$ & 0.6 & 0.8 & 1.0 \\
\hline Lama Pengeringan (Hari) & $\mathrm{D}$ & 3 & 5 & 7 \\
\hline
\end{tabular}

\subsection{Menentukan Othogonal Array}

Pada kasus ini dipilih $f=4, l=3$, sehingga diperoleh:

$$
\begin{aligned}
d b(l) & =l-1=3-1=2, \\
d b(O A) & =f \times d b(l)=4 \times 2=8, \\
n & =d b(O A)+1=8+1=9 .
\end{aligned}
$$

Pada Tabel 2 diberikan matriks orthogonal array $L_{9}\left(3^{4}\right)$ yang digunakan dalam kasus ini.

Tabel 2. Orthogonal Array $L_{9}\left(3^{4}\right)$

\begin{tabular}{|c|c|c|c|c|}
\hline \multirow{2}{*}{ Percobaan } & \multicolumn{5}{|c|}{ Faktor } \\
\cline { 2 - 5 } & A & B & C & D \\
\hline 1 & 1 & 1 & 1 & 1 \\
\hline 2 & 1 & 2 & 2 & 2 \\
\hline 3 & 1 & 3 & 3 & 3 \\
\hline 4 & 2 & 1 & 2 & 3 \\
\hline 5 & 2 & 2 & 3 & 1 \\
\hline 6 & 2 & 3 & 1 & 2 \\
\hline 7 & 3 & 1 & 3 & 2 \\
\hline 8 & 3 & 2 & 1 & 3 \\
\hline 9 & 3 & 3 & 2 & 1 \\
\hline
\end{tabular}

Hasil dari percobaan akan diuji dengan alat uji mesin press untuk mendapatkan nilai kuat tekan (MPa) dan diperoleh data hasil percobaan seperti pada Tabel 3.

\subsection{Perhitungan Efek Rata-rata Dan SNR}

Pada kasus ini perhitungan nilai rata-rata dan SNR digunakan software Minitab 16 sehingga diperoleh hasil pada Tabel 4.

Untuk mendapatkan nilai efek rata-rata dan SNR digunakan software Minitab 16 yang dapat dilihat pada Tabel 5 dan Tabel 6 . 
Tabel 3. Data Hasil Percobaan

\begin{tabular}{|c|c|c|c|c|c|c|c|}
\hline \multirow{2}{*}{ Percobaan } & \multicolumn{5}{|c|}{ Faktor } & \multirow{2}{*}{ Ulangan 1 } & \multirow{2}{*}{ Ulangan 2 } \\
\cline { 2 - 5 } & $\mathrm{A}$ & $\mathrm{B}$ & $\mathrm{C}$ & $\mathrm{D}$ & & & \\
\hline 1 & 10 & 0.4 & 0.6 & 3 & 0.3111 & 0.4000 & 0.3556 \\
\hline 2 & 10 & 0.6 & 0.8 & 5 & 0.4444 & 0.5778 & 0.4889 \\
\hline 3 & 10 & 0.8 & 1.0 & 7 & 0.5778 & 0.6222 & 0.7111 \\
\hline 4 & 12 & 0.4 & 0.8 & 7 & 0.2222 & 0.3111 & 0.2667 \\
\hline 5 & 12 & 0.6 & 1.0 & 3 & 0.4444 & 0.5333 & 0.7111 \\
\hline 6 & 12 & 0.8 & 0.6 & 5 & 0.5333 & 0.8000 & 0.6222 \\
\hline 7 & 14 & 0.4 & 1.0 & 5 & 0.3111 & 0.2667 & 0.2667 \\
\hline 8 & 14 & 0.6 & 0.6 & 7 & 0.2222 & 0.2667 & 0.3111 \\
\hline 9 & 14 & 0.8 & 0.8 & 3 & 0.6222 & 0.4444 & 0.4889 \\
\hline
\end{tabular}

Tabel 4. Rata-rata Nilai Percobaan dan $S N R$

\begin{tabular}{|c|c|c|c|c|c|}
\hline Percobaan & Ulangan 1 & Ulangan 2 & Ulangan 3 & $\bar{y}$ & $S N R$ \\
\hline 1 & 0.3111 & 0.4000 & 0.3556 & 0.3556 & -9.1190 \\
\hline 2 & 0.4444 & 0.5778 & 0.4889 & 0.5037 & -6.1073 \\
\hline 3 & 0.5778 & 0.6222 & 0.7111 & 0.6370 & -4.0117 \\
\hline 4 & 0.2222 & 0.3111 & 0.2667 & 0.2667 & -11.7264 \\
\hline 5 & 0.4444 & 0.5333 & 0.7111 & 0.5630 & -5.4636 \\
\hline 6 & 0.5333 & 0.8000 & 0.6222 & 0.6519 & -4.0717 \\
\hline 7 & 0.3111 & 0.2667 & 0.2667 & 0.2815 & -11.0785 \\
\hline 8 & 0.2222 & 0.2667 & 0.3111 & 0.2667 & -11.7264 \\
\hline 9 & 0.6222 & 0.4444 & 0.4889 & 0.5185 & -59584 \\
\hline
\end{tabular}

Tabel 5. Efek dari Rata-rata

\begin{tabular}{|c|c|c|c|c|}
\hline \multirow{2}{*}{ Level } & \multicolumn{4}{|c|}{ Faktor } \\
\cline { 2 - 5 } & $\mathrm{A}$ & $\mathrm{B}$ & $\mathrm{C}$ & $\mathrm{D}$ \\
\hline 1 & 0.4988 & 0.3012 & 0.4247 & 0.4790 \\
\hline 2 & 0.4938 & 0.4444 & 0.4296 & 0.4790 \\
\hline 3 & 0.3556 & 0.6025 & 0.4938 & 0.3901 \\
\hline Nilai Efek & 0.1432 & 0.3013 & 0.0691 & 0.0889 \\
\hline Ranking & 2 & 1 & 4 & 3 \\
\hline
\end{tabular}

Berdasarkan hasil analisa nilai efek rata-rata dan $S N R$ didapat rancangan usulan yang sama yaitu $A_{1}, B_{3}, C_{3}, D_{1}$ dan dapat diketahui bahwa faktor persentase semen dan agregat memiliki pengaruh yang cukup signifikan terhadap karakteristik kuat tekan batako.

Untuk perhitungan efek tiap faktor untuk tiap ulangan adalah dengan mencari 
Tabel 6. Efek dari $S N R$

\begin{tabular}{|c|c|c|c|c|}
\hline \multirow{2}{*}{ Level } & \multicolumn{4}{|c|}{ Faktor } \\
\cline { 2 - 5 } & $\mathrm{A}$ & $\mathrm{B}$ & $\mathrm{C}$ & $\mathrm{D}$ \\
\hline 1 & -6.413 & -10.641 & -8.306 & -6.847 \\
\hline 2 & -7.088 & -7.766 & -7.931 & -7.086 \\
\hline 3 & -9.588 & -4.681 & -6.851 & -9.155 \\
\hline Nilai Efek & 3.175 & 5.960 & 1.454 & 2.308 \\
\hline Ranking & 2 & 1 & 4 & 3 \\
\hline
\end{tabular}

nilai rata-rata respon dari tiap level faktor untuk tiap ulangan. Perhitungan efek faktor untuk tiap ulangan diberikan pada Tabel 7.

Tabel 7. Efek Tiap Faktor Untuk Tiap Ulangan

\begin{tabular}{|c|c|c|c|c|}
\hline Faktor & $\mathrm{A}$ & $\mathrm{B}$ & $\mathrm{C}$ & $\mathrm{D}$ \\
\hline Ulangan 1 & 0.0593 & 0.2074 & 0.0889 & 0.1185 \\
\hline Ulangan 2 & 0.2222 & 0.2963 & 0.0444 & 0.1481 \\
\hline Ulangan 3 & 0.1778 & 0.3111 & 0.1481 & 0.0889 \\
\hline Ranking & 2 & 1 & 4 & 3 \\
\hline
\end{tabular}

Berdasarkan Tabel 7 dipilih nilai efek terbesar untuk disarankan sebagai rancangan usulan. Rancangan usulan yang didapat yaitu $A_{2}, B_{3}, C_{3}, D_{2}$.

\subsection{Perhitungan Analisis Variansi}

Analisis variansi pada penelitian ini bertujuan untuk mencari atau mengetahui faktor-faktor yang signifikan berpengaruh terhadap kuat tekan batako. Untuk mengetahui faktor yang signifikan berpengaruh terhadap kuat tekan batako dilakukan perhitungan untuk analisis variansi sehingga diperoleh Tabel 8.

Tabel 8. Analisis Variansi

\begin{tabular}{|c|c|c|c|c|c|c|}
\hline SK & $d b$ & JK & KT & $F_{\text {ratio }}$ & JK' & $\rho$ \\
\hline Faktor A & 2 & 0.1193 & 0.0597 & 8.7222 & 0.1056 & 14.5827 \\
\hline Faktor B & 2 & 0.4084 & 0.2042 & 29.8587 & 0.3947 & 54.4971 \\
\hline Faktor C & 2 & 0.0263 & 0.0132 & 1.9228 & 0.0126 & 1.7427 \\
\hline Faktor D & 2 & 0.0470 & 0.0235 & 3.4362 & 0.0333 & 4.6006 \\
\hline Galat & 18 & 0.1231 & 0.0068 & & 0.1780 & 24.5770 \\
\hline Total & 26 & 0.7243 & & & & 100 \\
\hline
\end{tabular}

Berdasarkan Tabel 8, dapat diketahui bahwa nilai $F_{\text {Hitung }}$ faktor A dan B lebih besar dari nilai $F_{\text {Tabel }} F_{0.05(2,18)}=3,55$ maka Tolak $H_{0}$ sehingga dapat dikatakan 
bahwa faktor A dan B memberikan pengaruh yang signifikan terhadap karakteritik kuat tekan batako.

Urutan rancangan usulan yang memberikan kontribusi terbesar hingga terkecil menurut analisis ragam adalah B, A, D dan C. Berdasarkan analisis-analisis yang telah dilakukan dapat diperoleh ranking untuk setiap faktor yang ditampilkan pada Tabel 9.

Tabel 9. Ranking Pengaruh Tiap Faktor

\begin{tabular}{|c|c|c|c|c|}
\hline Ranking & Efek Faktor & Efek $S N R$ & Efek Tiap Faktor & Analisis Variansi \\
\hline 1 & B & B & B & B \\
\hline 2 & A & A & A & A \\
\hline 3 & D & D & D & D \\
\hline 4 & C & C & C & C \\
\hline
\end{tabular}

Berdasarkan Tabel 9 terdapat keseragaman rancangan usulan untuk karakteristik mutu kuat tekan batako yaitu jenis larger is better. Dari Tabel 9 dapat diketahui bahwa rancangan usulan untuk metode Taguchi adalah $A_{1}, B_{3}, C_{3}$ dan $D_{1}$.

\subsection{Uji Hipotesis}

Uji hipotesis dilakukan sesuai dengan rancangan usulan yang didapat $\left(A_{1}, B_{3}, C_{3}, D_{1}\right)$, yaitu agregat $=10 \mathrm{Kg}$, semen $=0.8 \mathrm{Kg}$, air $=1 \mathrm{~L}$ dan lama pengeringan $=3$ hari. Besaran rata-rata rancangan adalah:

$$
\begin{aligned}
\bar{x} & =\overline{A_{1}}+\overline{B_{3}}+\overline{C_{3}}+\overline{D_{1}}-(3 \times \bar{y}) \\
& =0.4988+0.6025+0.4938+0.4790-(3 \times 0,4494) \\
& =0,7259
\end{aligned}
$$

Setelah diketahui nilai rata-rata rancangan, percobaan konfirmasi dilakukan untuk membuktikan apakah prediksi hasil percobaan tersebut bisa tercapai. Percobaan konfirmasi pada penelitian ini adalah hasil produksi pabrik. Hasil percobaan konfirmasi yang diperoleh dalam Tabel 10 .

Tabel 10. Hasil Produksi Pabrik

\begin{tabular}{|c|c|}
\hline No & Hasil Uji Kuat Tekan \\
\hline 1 & 0.7111 \\
\hline 2 & 0.6222 \\
\hline 3 & 0.8000 \\
\hline Rata-rata & 0.7111 \\
\hline Standar Deviasi & 0.0079 \\
\hline
\end{tabular}

Untuk membandingkan hasil produksi pabrik dengan hasil percobaan, dilakukan 
uji hipotesis sebagai berikut:

$$
\begin{aligned}
& H_{0}: \mu=\mu_{0} \\
& H_{1}: \mu \neq \mu_{0}
\end{aligned}
$$

dimana

$H_{0}$ : nilai rata-rata hasil percobaan sama dengan nilai rata-rata hasil produksi pabrik

$H_{1}$ : nilai rata-rata hasil percobaan tidak sama dengan nilai rata-rata hasil produksi pabrik

Pada percobaan ini digunakan taraf uji $\alpha=0.05$ sehingga:

$$
\begin{aligned}
t_{\text {hitung }} & =\left|\frac{\bar{x}-\mu_{0}}{s / \sqrt{n}}\right|=\left|\frac{0.7259-0.7111}{0.0079 / \sqrt{3}}=3.2448\right| \\
t_{\text {tabel }} & =t_{\frac{\alpha}{2}(r-1)}=t_{\frac{0.05}{2}(3-1)}=t_{0.025(2)}=4.303
\end{aligned}
$$

Berdasarkan hasil yang diperoleh, $t_{\text {hitung }}<t_{\text {tabel }}$ maka Tidak Tolak $H_{0}$ sehingga dapat dikatakan bahwa data hasil percobaan dan data hasil produksi pabrik tidak berbeda jauh. Ini berarti rancangan usulan cukup memadai.

\section{KESIMPULAN}

Berdasarkan hasil penelitian yang telah dilakukan dapat disimpulkan bahwa faktorfaktor yang sangat mempengaruhi karakteristik kualitas kuat tekan (MPa) pada batako yaitu semen dan agregat. Rancangan optimal yang diusulkan berdasarkan hasil penelitian untuk satu buah batako adalah dengan level faktor yang terpilih $A_{1}$ $($ agregat $=10 \mathrm{Kg}), B_{3}($ semen $=0.8 \mathrm{Kg}), C_{3}($ air $=1 \mathrm{~L})$ dan $D_{1}($ lama pengeringan $=$ 3 hari). Untuk kuat tekan batako optimal yang didapatkan dari penelitian ini yaitu sebesar 0,7259 MPa. Hal ini menunjukkan bahwa dengan menggunakan metode Taguchi, diperoleh kualitas batako yang lebih baik daripada kualitas batako buatan pabrik.

\section{Daftar Pustaka}

[1] Asmasari. 2015. Aplikasi Metode Taguchi dan Penentuan Quality Loss Function Pada Karakteristik Mutu Larger is Better. Makassar: Skripsi Universitas Hasanuddin.

[2] Roy, Ranjit K. 1990. A Primer On The Taguchi Method. Van Nostrand Reinhold. New York. 